\section{Dystonic reaction (forcible protrusion of the tongue) of over six months' duration DeAR SIRS successfully treated with Benzhexol}

A thirty-year-old woman with mild mental subnormality and classical Schneiderian symptoms of schizophrenia was referred in August 1984. She also presented with a protruding oedematous and inflamed tongue which she was unable to keep within her mouth for long.

The patient's relatives indicated that she had been under the care of a traditional healer who had administered a herbal extract (probably Rauwolfia Serpentina) to her. This appeared to have caused the protrusion of her tongue, which had lasted for over six months.

Within three months her tongue protrusion had responded to a course of benzhexol $5 \mathrm{mg}$ thrice daily gradually increasing to $10 \mathrm{mg}$ thrice daily. In addition, she received a week's course of Chymoral (a proteolytic enzyme with strong anti-inflammatory effect) tablets-2 tds and ascorbic acid $200 \mathrm{mg}$ tds for two weeks. Her psychosis was controlled with chlorpromazine and haloperidol, $100 \mathrm{mg}$ tds and $5 \mathrm{mg}$ bd respectively.

I am not aware of any report of such a protracted case of drug-induced tongue protrusion. The successful treatment of this case indicates that anti-cholinergic drugs such as benzhexol given in high doses would resolve this condition irrespective of its duration. This case may be of interest to colleagues in developing countries where a vast majority of mental patients are first seen by traditional herbalists and may present at hospitals with complications arising from herbs administered.

IKECHUKWU JOHN NEBUWA

Psychiatric Hospital

Enugu, Nigeria

\section{Reviews}

Guidelines for Investigating Alcohol Problems and Developing Appropriate Responses by Irving Rootman and Joy Moser. WHO Offset Publication No 81. WHO, Geneva. 1984. Pp 120

In 1976, the World Health Organisation set up a project entitled 'Community Response to Alcohol Related Problems'. The countries involved, or at least giving support, included the United States, Mexico, the United Kingdom and Zambia. The United Kingdom was represented by Scotland. The aim was 'to develop approaches for coordinated research and action, concerning alcohol-related problems and responses to them in communities with different socio-cultural settings.'

This document appears to be guidelines that emerged during this project, both in terms of methods of investigation of alcohol problems and also the development of responses, and it was felt that these guidelines would be of wider interest than in the countries mentioned above, i.e. they would have value in other countries. It was also claimed that the document would be aimed primarily towards developing countries. Such a 'document' should be practical, well referenced and simple to use.

In essence, therefore, this document is meant to act as a guideline for workers in the field, in a variety of countries.

It is stated that in developing such a project, there are various stages of development. These include the initiation of a project, detailed planning, methods of gathering information, methods of improving existing responses to alcohol problems and the monitoring and assessment of such responses. Finally, there should be a willingness to constantly adjust such responses. These stages are usefully summarized in diagrammatic form, and in relation to the last three stages, it is emphasized that one has to differentiate between developments at local and at a national level. They also stress two further principles. Firstly, "there should be an integral relationship between research and action, neither one proceeding in the absence of the other'; and secondly, 'community participation is critical in all stages of the project described.'

Six different methods are used and described in detail in separate annexes to the report in detailed planning. These include: methods of collating existing information; key informant studies (where key people in the community are asked for information about alcohol-related problems); observational studies (where direct observational studies are made of drinking patterns, etc); general and specific population studies; and the use of reporting systems. The latter seems a recent development and is described as 'an information system based on reports admitted to a central body, using a systematic reporting procedure'; an example of this would presumably be something akin to the existing systems of reporting drug addicts to the Home Office by clinicians. In the annexes each of these six methods of obtaining information are extensively and critically reviewed, with the advantages and disadvantages of each method examined. This is also usefully shown in tabular form.

Having initially examined methods of investigating alcohol problems, the remainder of the report examines methods of improving responses to alcohol problems, distinguishing between action at local level and at national level. Action at local level obviously involves control of availability, public education, provision of alternative forms of recreation and methods to help those individuals locally who are identified as having drinking problems. The techniques suggested include, perhaps inevitably, the idea of an alcohol problem team in the community, but also the use of primary health care workers.

In relation to action at national level, this again relates to national reductions in supply and reduction in demand, and also the management of people identified with alcoholrelated problems. 
The report is written in the bureaucratic language, inevitable in such reports, although it is clear and largely can be read by a non-specialist. It inevitably has a 'common denominator' feel about it, although this is not as evident as in some other similar reports; it is also somewhat idealistic. It would be interesting to know how the different countries were chosen-no information is given on this at all. There also seems to be insufficient awareness of the real difficulty of interesting workers, including primary care workers and local or national governmental agencies in alcohol-related problems. At national level, the inherent problems (certainly in Western Europe) that governments face lie between, on the one hand, promoting reduction in alcohol consumption, and on the other, the fact that the effect this may have on unemployment and revenue are insufficiently stressed. In the detailed information provided, there is also the irritation of quoting frequent references which are unpublished. These are references to reports which have evolved during the project and are not yet published.

Despite these criticisms, this is an important report, which clearly is the result of a great deal of work by the participants and their advisers and will, I believe, serve as a very useful guideline to those individuals and agencies who are trying in many countries in the world to investigate the problems of alcohol misuse.

Withington Hospital, Manchester

B. D. HORE

Community in Social Policy by Peter Willmott and David Thomas. Discussion Paper No 9. Policy Studies Institute. 1984, Pp. 58. £1.50.

Few would quarrel with the proposition that 'the community' is a good thing. For, as Raymond Williams suggests, ${ }^{1}$ it is a 'warmly persuasive word' and across the political spectrum its connotations arouse nostalgic and folksy notions of gemeinschaft, of decentralization and of authentic human relations.

This discussion paper of the Rowntree Trust examines the concept, one which has been current in psychiatry since the late 1950s as the rationale behind the provision of alternatives to existing hospital-based facilities. Willmott suggets 'the community' came into prominence after the war with the decay of homogeneous areas characterized by common residence, occupation and work, and with the growth of large local government areas and the associated impersonal administration of the welfare state, health services and inner-city redevelopment. In other words we discovered 'the community' when actually existing communities had declined and their functions taken over by the state.

Current use of the notion of 'the community' includes: (a) the public in general; (b) cultural or other minorities (the 'gay community'); (c) a 'softened' public image ('community homes' rather than 'approved schools'); (d) locally organized small-scale facilities, pressure groups or activities, orientated to residence or common interest ('patch' based social services, tenants' associations, community arts). Primarily associated with shared residence, the term implies shared patterns of sentiments, behaviour and lifestyle, and close and frequent personal relations with others. Common interests reflect class, occupational and ethnic homogeneity, or shared adversity. Whilst some commentators have felt the term to be too inclusive and too value-laden to have any real validity, and have proposed instead the substitution of 'local' or 'common interest', the idea seems too good to lose, precisely because of its elasticity and favourable evaluative loading. The explicit goals of a richer, more fulfilling 'community' life and of social participation are not likely to be disputed. But, as Willmott notes, few activities carried out under the 'community' rubric are likely to affect root issues of poverty or unemployment.

To what extent do communities still have an actual existence? A MORI poll in 1982 suggested that more than half the population knew the names of at least eleven neighbours and talked to at least one on any day. The majority of the population still feel a shared 'attachment' to their neighbourhood.

The experience of 'common adversity' remains a powerful potential tool for community mobilization, as in the mining villages affected by pit closures, or even the sentiments engendered across party lines by the threatened, if considerably more impersonal, GLC. The idea that 'community' implies adversity is also one employed from outside by professionals. Thus the inner-city areas, characterized by the 'symptoms' (as Willmott terms them) of unemployment, poverty and poor housing are regarded by policy-makers as 'communities' in a way that is not true of the more affluent suburbs. Psychiatrists retain an image of them as more collective and homogeneous, possessing a 'culture' of potential psychopathological import, unlike the suburbs. Paradoxically, they seem to be weak as communities and thus we employ community workers to work inside the community, locating its problems in this culture, rather than looking at how the community is itself generated through national policy.

The discussion paper traces all too briefly the development of such institutions as community arts, community policing, community education, community care and community media. The ambiguity of the notion of community' is illustrated by its appropriation for commercial radio as opposed to state broadcasting. Similarly, as Sedgwick' ${ }^{2}$ has suggested, 'community psychiatry' carries the evaluative connotation of 'deinstitutionalization', whilst in fact frequently representing the replacing of public concern by the voluntary sector, the family or indeed by nothing.

\section{ROLAND LITTLEWOOD}

\section{Guy's Hospital, London SEI}

\section{REFERENCES}

'Williams, R. (1976) Keywords. London: Fontana/Croom Helm. ${ }^{2}$ Sedgwick. P. (1982) Psicho Politics. London: Pluto. 